تأثثر استخلم منهج (غذائي - بذني) في مكونات اللياقة الصحية وخفض الوزن للنساء البدينات

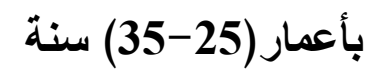

آمنة اياد سلمان (1)، حميد عبدالنبي عبدالكاظم الفتلاوي (2)

تأريخ تقديم البحث: (2020/5/21)، تأريخ قبول النشر (2020/7/27).

DOI: $\underline{\text { https://doi.org/10.37359/JOPE.V32(3)2020.1015 }}$

\title{
المستخلص
}

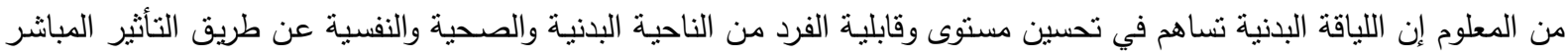

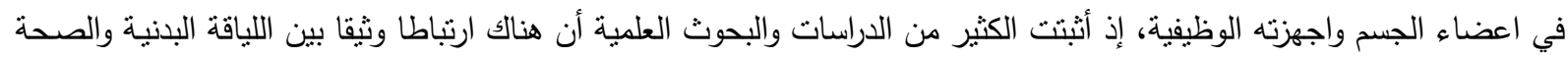

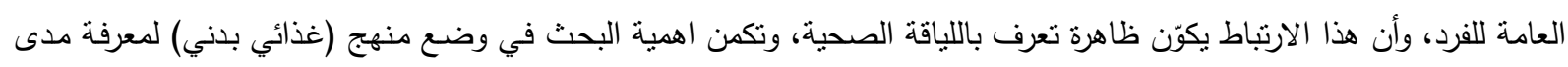

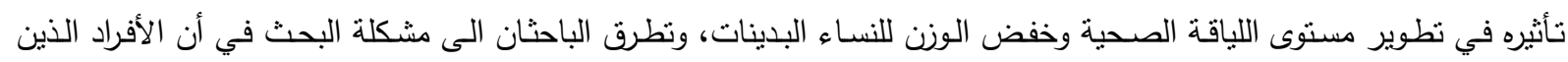

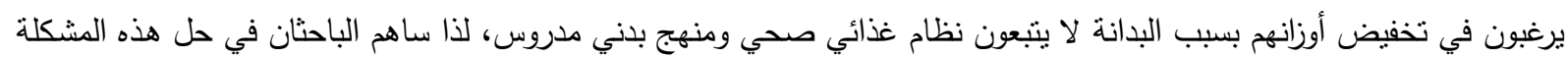

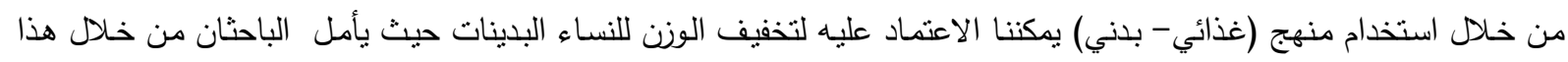

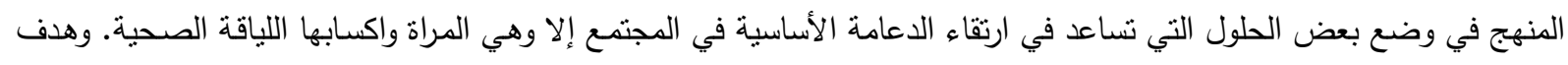

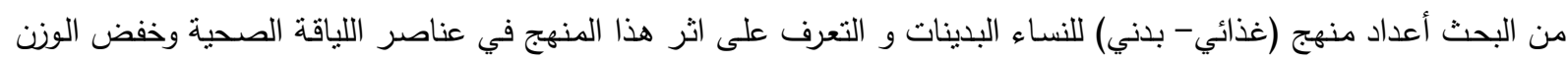

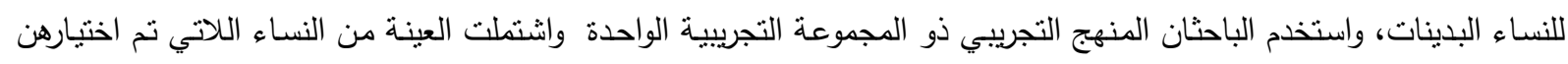
بطريقة العشوائية من المراجعات لمعهد بحوث التغذية في العيادة التخصصية لعلاج البدانة وعددهن (6) نساء التهات واعمارهن (25-35) سنة. واجرت عليهم الاختبارات القبلية وتم تطبيق المنهاج بواقع ثنلاث وحدات في الاسبوع ولمدة شهران وتم اجراء الاء الاختبارات البعدية

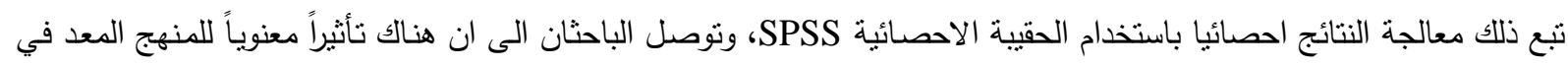

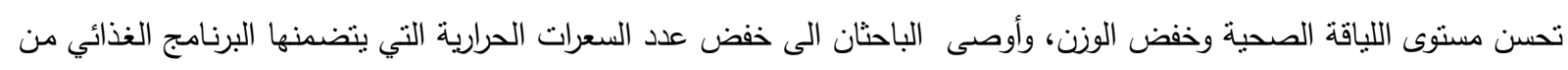

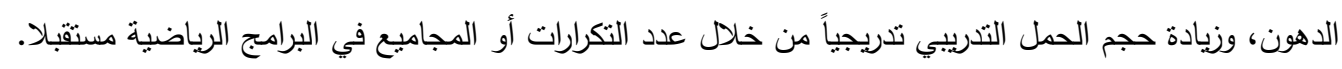
الكلمات المفتاحية: اللياقة البدنية المرتبطة بالصحة، السمنة، سمنة النساء، فقدان الوزن.

\section{ABSTRACT \\ The Effect of Using Nutritional - Physical Program on Health Related Fitness components and Losing Weight in Obese Women Aged (25 - 35) Years Old}

The problem of the research lies in women wanting to lose weight yet unable to maintain a healthy nutritional program along with physical program. The research aimed at deigning a nutritional physical program for obese women as well as identifying its effect on health related fitness development and losing weight in obese women. The researchers used the experimental program on (6) obese women aged (25-35) years old from the nutritional researchers' institute in the specialized clinic for treating obesity. The training program lasted for three sessions per week for two months to conclude that the program have a positive effect on improving health relate fitness and losing weight. Finally the researchers recommended decreasing calories and increasing training load gradually through repetitions in future athletic programs.

Keywords: health related fitness, obesity, women's obesity losing weight.

(1) طالبة دراسات علبا (الدكتوراه)، جامعة بغداد، كلية التربية البننية وعلوم الرياضة. (Palmanamna296@gmail.com) Amena Ayad Selman, Post Graduate Student (P.HD), University of Baghdad, College of Physical Education and Sport Sciences, (salmanamna296@gmail.com) (+9647711142040).

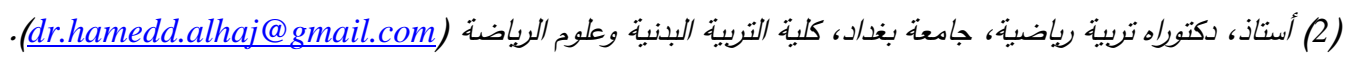
Hameed Abdul Nebi Abdul Khadem, Prof (PH.D), University of Baghdad, College of Physical Education and Sport Sciences, (dr.hamedd.alhaj@gmail.com) (+9647703159159). 
تعد الصحة من اهم عناصر واستمرارالانسان في الحياة والقيام بأعماله اليومية مع تأخير الثعور بالتعب وهذه نعمة

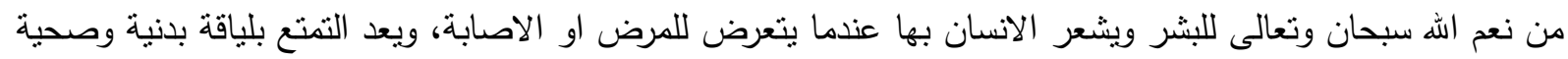
جيدة مؤشرا مهما من مؤشرات الصحة وامتلاك متل هذه اللياقة له اثر ايجابي في دور الانسان في حياته اليومية وفي لهي المجتمع ككل. وبشكل عام مجتمعنا اكتر عرضة للإصابة بالبدانة بسبب قلة مؤنة نشاطها البدني وتتاول الغذاء المحمل

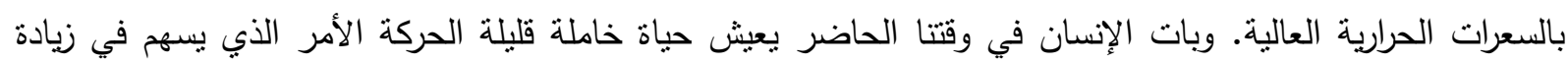

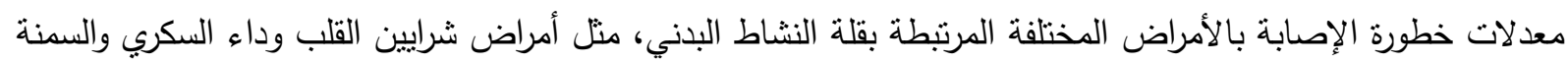

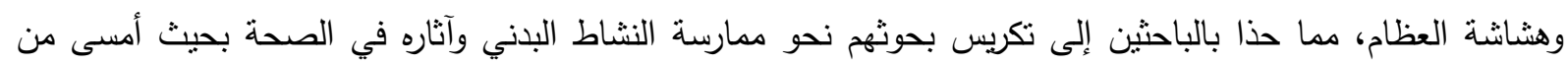
أولويات الصحة العامة. ولقد تطرقت العديد من الدراسات حول البرامج الغذائية والرياضية وعناصر اللياقة المرتبطة بالصحة لعلاج البدانة

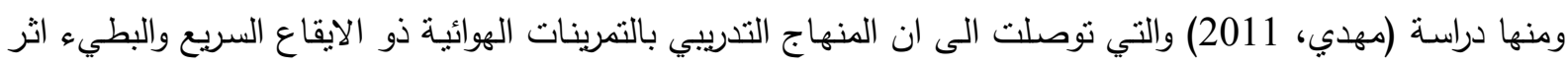

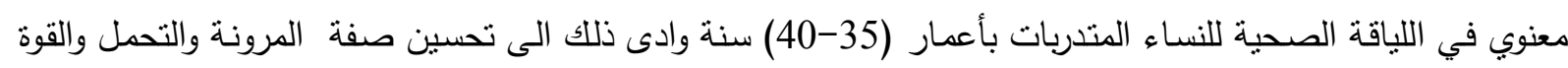

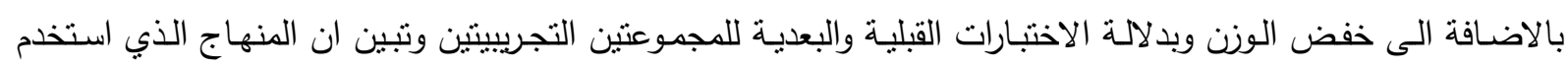
تناسب مع عينة البحث وظهر ذلك من خلال النتائج إذ تنين انه فعال قي خفض مستوى الثحوم وتحسين مستوى العناصر المرنبطة بالصحة للنساء البدينات وادى الى حصول تطور ملحوظ في نزول الوزن. اما دراسة (فتحي، 2002) فقد توصلت الى ان البرنامجين الغذائي والغذائي الرياضي اديا الى خفض نسبة الدئية الدهون ووزن الدهون وتحسين مستوى اللياقة البدنية

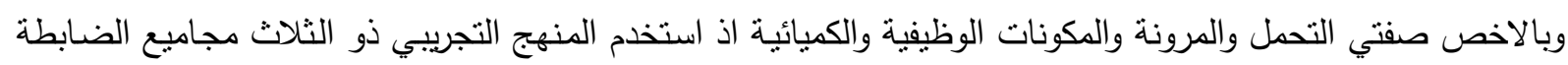
ومجموعة تجريبية نفذت البرنامج الغذائي وتجريبية ثانية نفذت البرنامج الغذائي الرياضي وحققت المجموعة التجريبية الثانية

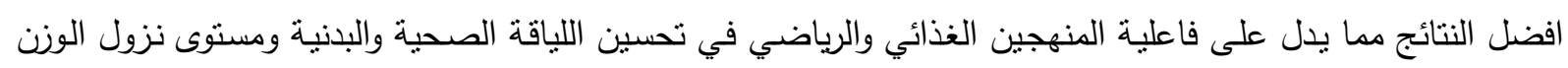
وخفض المكون الثحمي. اما دراسة (علي، 2016) فقد توصلت الى ان هنالك تأثير معنوي لتمارين الايروبك في تحسين وتطوير اللياقة الصحية وبالذات صفة القوة العضلية والتركيب الجسمي وظهر ذللك بشكل واضح في قياسات المحيطات للجسم اذ استخدمت الايقاعات الموسيقية والمتدرجة من الايقاع البطيء الى الايقاع السريع والمتدرج الثندة.

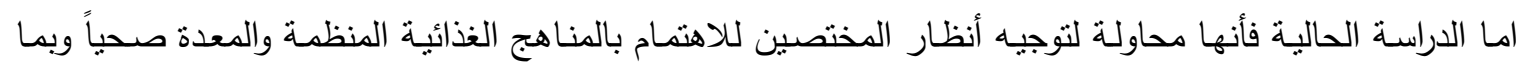

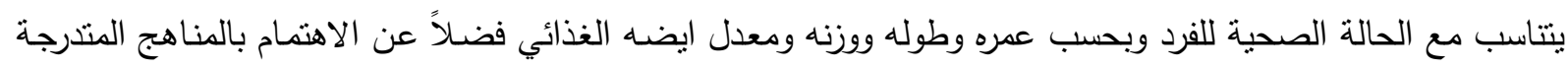

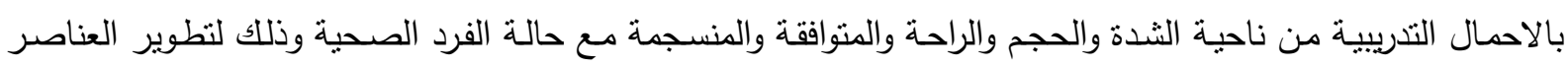
البدنية والصحية للفرد وخفض الوزن.

\section{الطريقة والادوات:}

استخدم الباحثان المنهج التجريبي ذو تصميم المجموعة الواحدة. وتكونت عينة البحث من النساء اللاتي تم اختيارهن

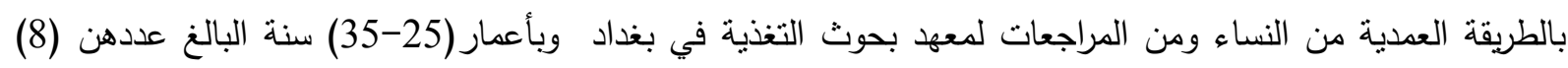

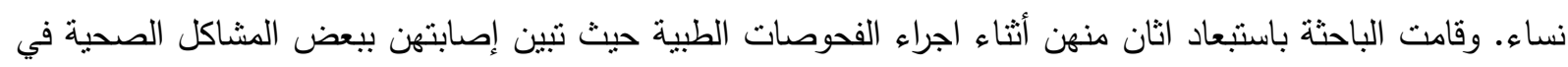

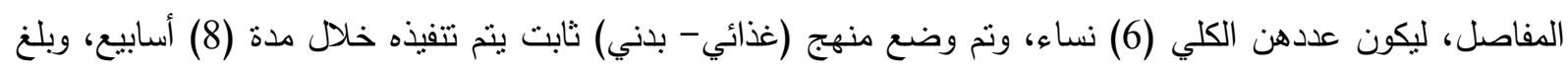

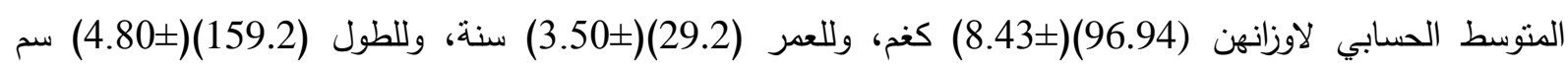
وكانت العينة ضمن التوزيع الطبيعي. 
م اختبار قوة القبضة (الهزاع، 2001، صفحة 13):

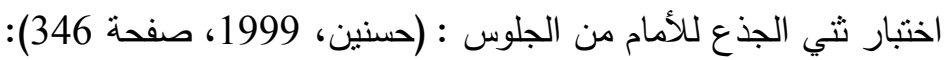

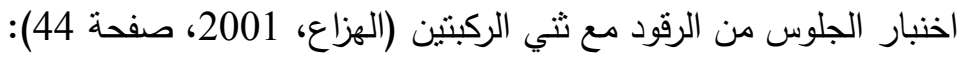

وأجرى الباحثان تجربـة استطلاعية على (3) نساء من خـارج عينـة البحث، للتأكد من صـلاحية الأجهزة والأدوات

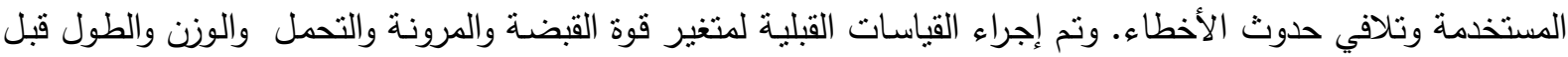
البدء بتفيذ المنهج (الغذائي- البدني)، وشرح كافة التفاصيل الخاصـة بـه لعينة البحث، وحاول الباحثان جاهدين تسيير

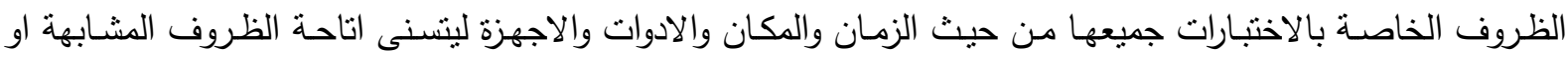
المقاربة عند اجراء الاختبارات البعدية.

واعتمد البحاثان على الخبراء والمصادر العلمية والخبرة الثخصية في اعداد وتصميم المنهج البدني وهذه التصرينات

اعدت بما يناسب عمر العينة وقد راعى الباحثان في تطبيق المنهج الاسس الاتية:

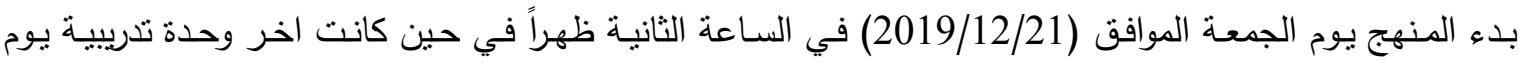
الاربعاء الموافق (2020/2/19) الساعة الثانية ظهراً. لقد استغرقت مدة المنهج (8) اسابيع وبواقع (3) وحدات تدريبية في الاسبوع ولأيام (الجمعة -الاحد - الثناثاء). عدد الوحدات التدريبية (24) وحدة تدريبية. اعتمد الباحثان مبدأ التدرج في اعطاء الثدة وبما ان العينة من المبتدئين فقد بدأ المنهج بشدة (50\%) وتزداد الثدة

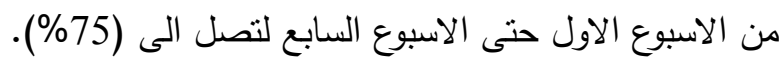
تم الاعتماد على معدل النبض لحساب الثدة وفق معادلة (220- العمر). ان المنهج شمل نسبة عالية من الحركات الخاصـة بعمل العضلات الكبيرة بالجسم لكونها مؤشراً هاماً في رفع قدرة

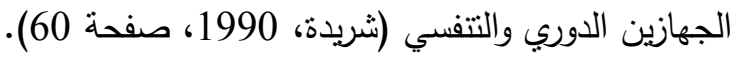
يحتوي المنهج على حركات متتوعة بحيث نتتاسب وقدرات المتدربات في هذه المرحلة العمرية. الزمن الكلي للوحدة التدريبية الواحدة (35-40) دقيقة متضمنا زمن الاحماء والتهيئة وكان من ضمن الاحماء تمرينات للتمطية. اذ بلغ زمن الاحماء (15) دقيقة وزمن الجزء الرئيسي(15-25) دقيقة وزمن التهدئة (10) دقيقة.

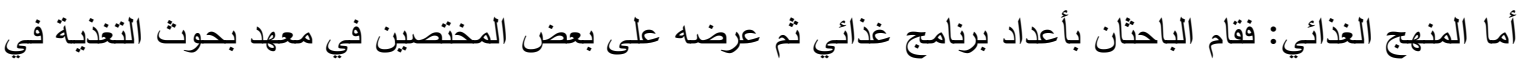

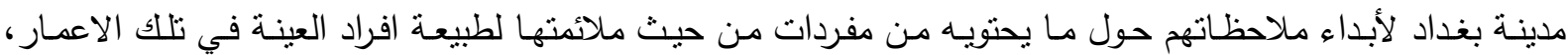
واحتوائها على العناصر الغذائية الاساسية والضرورية للفرد، وكمية السعرات الحرارية التي تحنويها كل مادة، وبعد ان اطلع الباحثان على ملاحظاتهم، قاما بأجراء بعض التعديلات اللازمة ليكون البرنامج بصيغته النهائية وقد امتاز البرنامج الغذائي بالتتوع، وتم حساب معدل التمثيل الغذائي لكل امراءة عن طريق ا معادلة هاريس بينديكت لحساب كيّّة السعرات الحراريّة المحروقة خلال اليوم، وبالتالي معرفة الاحتياجات اليومية من السعرات الحراريّة لكل امراة (Benedict, 2019) ، وامتاز المنهج بما يلي: يحتوي على اطعمة قلبلة السعرات الحرارية، اذ ركز الباحثان على الاغذية الليفية، والتي تتميز بقلة سعراتها الحرارية، واخذها حيز كبير في المعدة، مما يشعر الفرد بالثبع بسرعة، حيث تؤكد المصادر العلمية على اهمية الاغذية الليفية

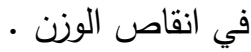
يحتوي على اطعمة مختلفة المذاق ومناسبة للأفراد، وتؤدي الى الاحساس بالثبع بسرعة. 
مناسبة لمستوى معيشة الفرد، وسهولة الحصول عليها وعدم ارتفاع اسعارها.

يحتوي على عناصر الغذاء الاساسية (الكاربوهيدرات والبروتينات والدهون).

وضـع السعرات الحراريـة لكل مادة غذائية، بحيث يكون مجموع السعرات التي يفقدها الفرد تسمح بفقدان الوزن بما لايزيد عن(0.5-1) كغم اسبوعيا، وهذا ما تؤكده المصادر العلمية لكي يكون الوزن المفقود من شحوم الجسم وليس

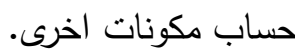
لقد حرص الباحثان بأن يكون هذا البرنامج هو اسلوب ونمط حياه الفرد اليومي، والابتعاد عن العـادات الغذائية السيئة.

التقليل من كمية السكريات البسيطة، وكمية الدهون في الوجبات الغذائية، بحيث اعتمد السكريات المعقدة والموجودة في كل من الخبز والخضروات. ولضمان تطبيق البرنامج الغذائي فقد قام الباحثان بعمل الاجراءات التالية:

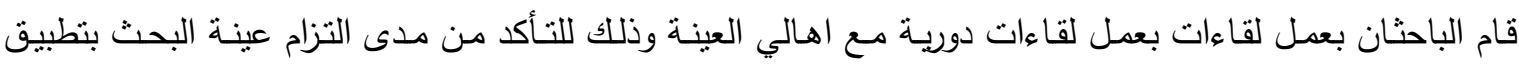

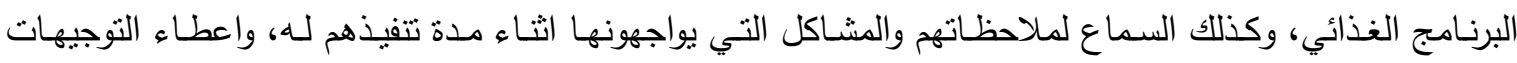
اللازمة والتي تضمن تتفيذ البرنامج بصورة سليمة، وفي كل لقاء كان الباحثان يوضحان اهمية الحفاظ على صحتهم

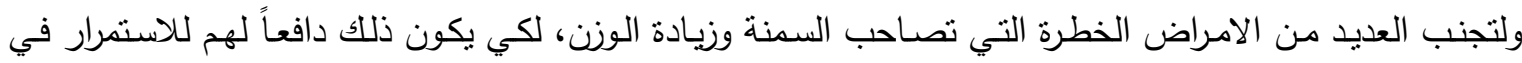
تطبيق البرنامج بصورة دقيقة. ومن الامور المهمة التي تؤكد عليها جميع المصادر العلمية عند نطبيق برامج تخفيض الوزن، هو وجود الرغبة لدى الافراد في فقدان اوزنهم، وكذلك رغبة الاهل في الاشتراك بمثل هذه البرامج إذ لمس الباحثين ذلك من خلال اللقاءات الاسبوعية والاتصالات الهاتفية معهم. وتم إجراء القياسات البعدية بعد الانتهاء من تتفيذ المنهج (الغذائي- البدني) وتسلسل الاختبارات والقياسات القبلية. نفسها. واستخدم الباحثان الحقيبة الإحصائية (SPSS) لمعالجة نتائج البحث.

النتائج: الجدول (1) يبين البيانات الوصفية واختبار الفروق بين نتائج الاختبارين القبلي والبعدي

\begin{tabular}{|c|c|c|c|c|c|c|c|}
\hline مستوى الخطأ & قيمة t & & فَ & $\varepsilon^{ \pm}$ & سَ سَ & الاختبار & الاختبارات \\
\hline \multirow{2}{*}{0.000} & \multirow{2}{*}{8.534} & \multirow{2}{*}{5.645} & \multirow{2}{*}{19.667} & 12.073 & 96.833 & قبلي & \multirow{2}{*}{ (كغن) } \\
\hline & & & & 7.985 & 77.166 & بعدي & \\
\hline \multirow{2}{*}{0.017} & \multirow{2}{*}{3.521} & \multirow{2}{*}{7.420} & \multirow{2}{*}{10.666} & 5.344 & 24.833 & قبلي & \multirow{2}{*}{ فوة القبضة } \\
\hline & & & & 3.391 & 35.500 & بعدي & \\
\hline \multirow{2}{*}{0.003} & \multirow{2}{*}{5.367} & \multirow{2}{*}{4.412} & \multirow{2}{*}{9.667} & 3.444 & 23.333 & قبلي & \multirow{2}{*}{ المرونة } \\
\hline & & & & 3.741 & 33.000 & بعدي & \\
\hline \multirow{2}{*}{0.001} & \multirow{2}{*}{6.778} & \multirow{2}{*}{2.228} & \multirow{2}{*}{6.166} & 1.329 & 9.833 & قبلي & \multirow{2}{*}{ (تكرار) } \\
\hline & & & & 1.264 & 16.000 & بعدي & \\
\hline
\end{tabular}

" معنوي عند مستوى الخطأ (0.05) اذا كان مستوى الخطأ اصفر من (0.05). 
من خلال الجدول اعلاه يتبين من نتائج الاختبار البعدي لعينة البحث انخفاض الوزن والسبب يعود الى حدوث خلل

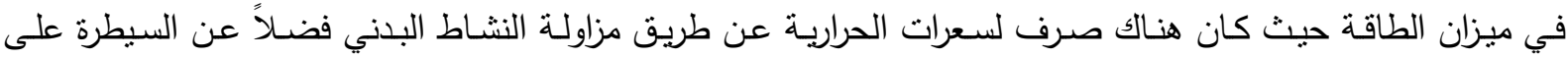

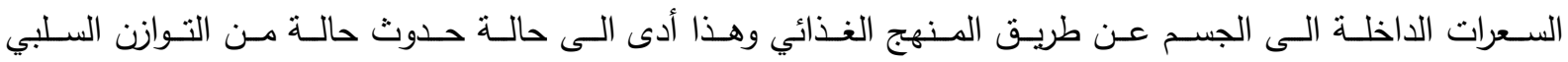
والتي تعرف بأنها حالة استهلاك للسعرات الحرارية بمعدل يفوق عدد السعرات الداخلة للجسم. (Energy Balance) (wilmore, 1977, p. 73) كما وان ممارسة النشاط البدني المتوسط الثدة الهوائي يعمل على دخول اكبر كمية من الأوكسجين الذي يؤدي إلى صرف مقدار اكبر من كمية دهون الجسم، (عرب، 2001، صفحة 85)، ونتيجة استخدام المنهج ( الغذائي - البدني) حدث انخفاض في الوزن، اذويرى (كسرى احمد فتحي) أن انخفاض وزن الجسم ناتج عن الانخفاض الايجابي لوزن الدهن

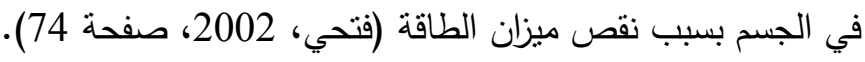
ويضيف الباحثان ان نزول الوزن مربوط بتقليل الطعام الداخل الى الجسم وممارسة النشاط البدني بالتدريج للمساعدة على نزول الوزن بشكل صحي ومنتظم لضمان عدم حدوث أي انتكاسة للشخص البدان انين.

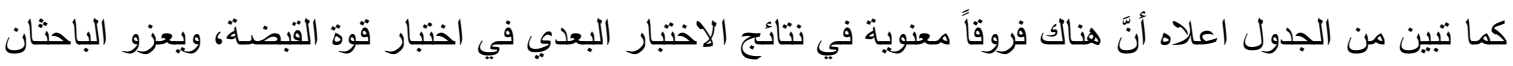

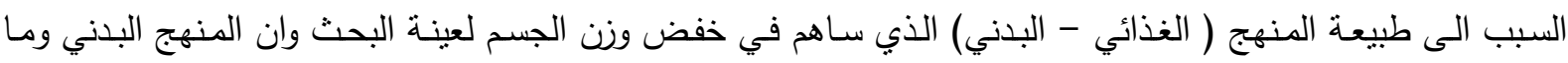
يحتويه من تمرينات كان ذا فائدة بالرغم من قلة الوحدات التدريبية المستخدمة التي هي من الامور المهمة في تطوير قوة

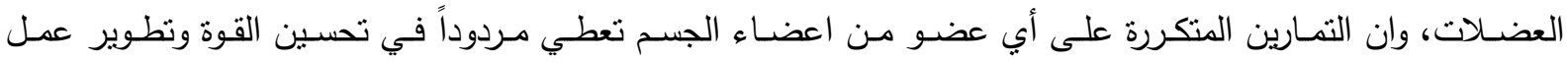

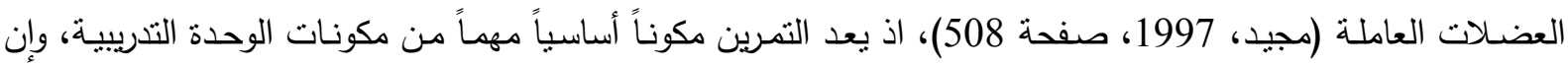

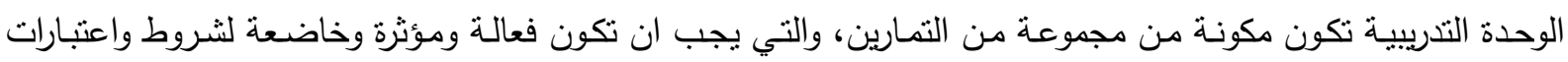
أساسية (محمد، 2000، صفحة 19). ويعزو الباحثنان سبب ظهور الفروق المعنويـة في اختبار المرونـة إلى تأثثر التمـارين البدنية التي احتواهـا المنهج

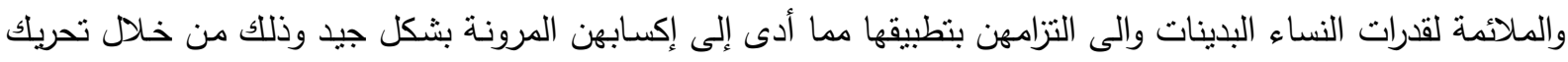

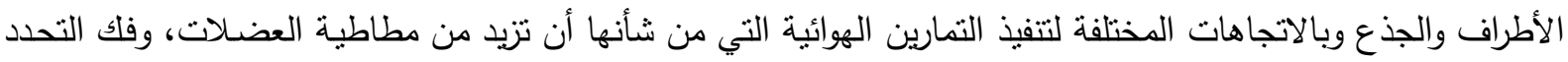
الحاصل في المفاصل بسبب الثد الحاصل على الأربطة والأوتار العضلية، إذ استعملت الباحثة تمارين الإطالة العضلية

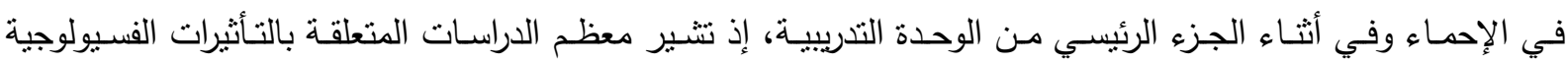

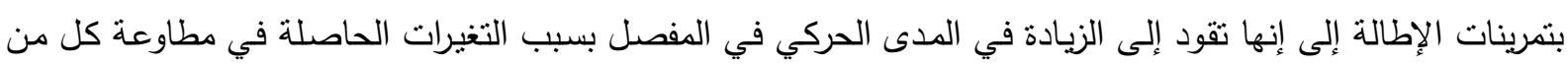

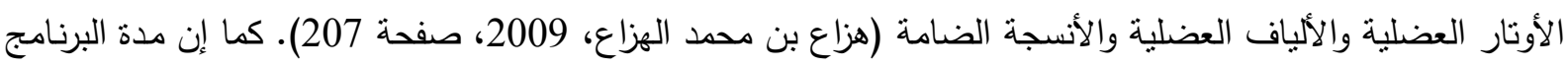

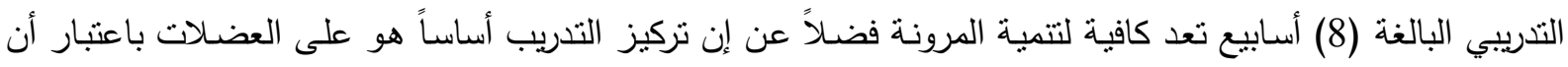

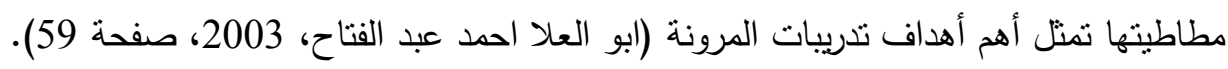
ويعزو الباحثان سبب ظهور الفروق المعنوية في اختبار تحمل قوة عضلات البطن الى تطبيق التمارين ضمن المنهج

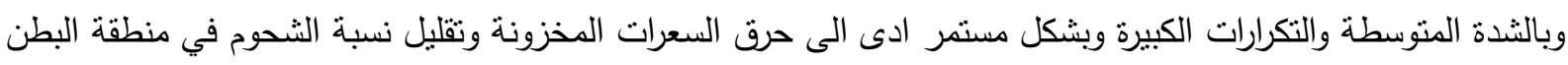
الامر الذي ادى حدوث تطور وتكيف للعضلات العاملة في منطقة البطن والاعتماد على الخزين من الدهون لانتاج الطاقة (قاسم، 2003، صفحة 128).. 
ومن خلال عرض النتائج وتحليليها ومناقتنها توصل الباحثان الى ان المنهح (الغذائي- البدني) الى تحسين مستوى اللياقة الصحية للنساء البدينات وخفض الوزن. وكان للمنهج ثاثيراً معنوياً في كل من الاختبارات (الوزن، قوة القبضة، المرونة، التحمل) ولصالح الاختبار البعدي مما يستوجب ضرورة اللجوء الى الطريقة المشتركة بين بين البرنامج الغائي

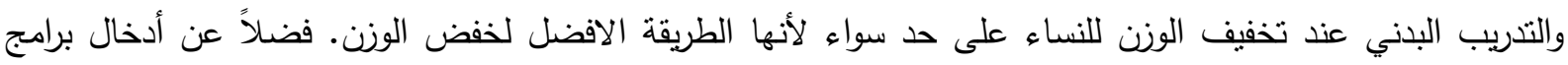
اللياقة البدنية والصحية في الكليات والمعاهد والمدارس وفي مختلف مجالات العمل لرفع وتطوير المستوى الصحي والبدني

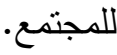

\section{المصادر}

احمد نصر الدين ابو العلا احمد عبد الفتاح. (2003). الرياضة وانقاص الوزن الطريق الى الرشاقة والصحة . القاهرة : دار الفكر العربي. زينة ابراهيم مهدي. (2011). تأثثر تمرينات هوائية بأستخدام ايقاعات في نطوير مؤشرات اللياقة المرتبطة بالصحة

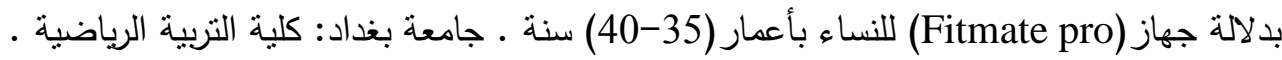
شيماء ناصر علي. (2016). تأثير منهج ندريبي لتمرينات الايروبك على بعض مكونات اللياقة الصحية. مجلة كلية التربية الاساسية. فاتن اسماعيل محمد. (2000). اثر تداخل اساليب التمرينات في التعلم ونقل اثره الى بعض المهارات الاساسية في

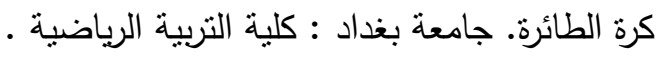
فاضل سلطان شريدة. (1990). وظائف الاعضاء والتدريب البدني . ط1. دار الهلال للاوفس. فريق فائق قاسم. (2003). تأثير منهج تدريبي مقترح لنطوير بعض الصفات البدنية الخاصة وعلاقتها بمستوى اداء مسكات الرمي الخطف بالمصارعة الرومانية فئة الناشئين بأعمار (16-17)سنة ـ جامعة بغداد : كلية النربية الرياضية . كسرى احمد فتحي. (2002). اثر برنامج غذائي -غذائي رياضي على عدد من المكونات الوظيفية والكميائية

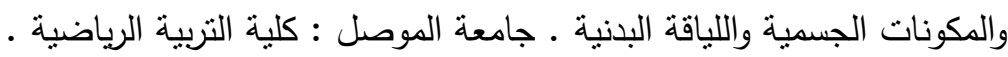
ريسان خريبط مجيد: تطبيقات في علم الفسيولوجيا والنتريب الرياضي، ط1، عمان ، دار الثروق للنشر، محمود سليمان عرب: أثز برنامج بدني وغذائي في المكونين الثحمي والعضلي وبعض متغيرات جهازي الدوران

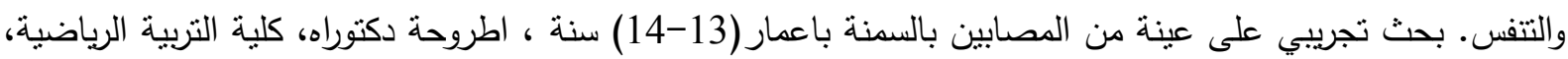
جامعة بغداد،

محمد صبحي حسنين. (1999). القياس والثقويم في التربية الرياضية والبدنية (المجلد ط1). القاهرة: دار الفكر العربي.

مفتي ابراهيم محمد عبدة صالح. (1994). اساسيات كرة القم. القاهرة : دار المعرفة . هارا. (1999). علم التدريبي الرياضي (المجلد ط1). بغداد: دار الكتاب للنشر والطباعة. هزاع بن محمد الهزاع. (2001). الدليل الارشادي لاختبار اللياقة البدنية المرتبطة بالصحة لدول مجلس التسبر التعاون للفئات العمرية(7-18) سنة (المجلد ط1). الرياض: دار المطابع للنشر .

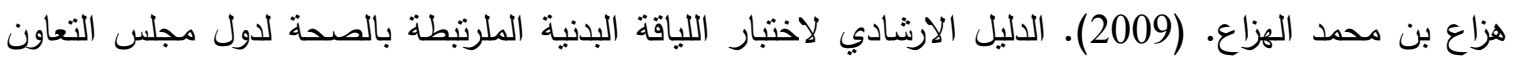
للفئات العمرية من 7-18 سنة (المجلد الاولى). الرياض، المملكة العربية السعودية : دار النشر والمطابع. .Allyn and Bocan .Athhletic training and physical fitness •. (1977) .ack wilmore Harris benedict -basal metabolic rate calorie calc", www.globalrph.com, 20-05-2019. 
الملاحق

الملحق (1) يوضح النظام الغذائي لعينة البحث

\begin{tabular}{|c|c|c|c|c|c|c|c|}
\hline السكر & السعرات & كاربوهيدرات & غ ن & غروتين & غ الوزن ب & الحجم & المادة الغذائية \\
\hline & & & & & & & الفطور \\
\hline 12,3 & 122 & 11,6 & 4,8 & 8,1 & 244 & كوب & حليب قليل الدسم \\
\hline 0,12 & 155 & 0,12 & 10,6 & 12,6 & 100 & 2 بيضة & بيض سلق \\
\hline 1,6 & 69,2 & 11,6 & 0,9 & 3,6 & 28 & ربع قطعة & خبز اسمر \\
\hline \multirow[t]{4}{*}{20,3} & 90,2 & 74,79 & 0,15 & 1,81 & 100 & 4 حبات & تمر \\
\hline & & & & & & & الغداء \\
\hline & 150 & 5 & 5 & 2,5 & 141,75 & 5 ملاعق & تبولة \\
\hline & 410,8 & 89,02 & 0,88 & 8,5 & 316 & كوبان & ارز مطبوخ \\
\hline \multirow[t]{4}{*}{0,12} & 337,2 & 80,8 & 0,18 & 30,6 & 265,5 & ونصف & مرق فاصوليا \\
\hline & 186,15 & 48,22 & 0,18 & 0,99 & 255 & كوب & عضير فواكه \\
\hline & \multicolumn{7}{|r|}{ العشاء } \\
\hline & 193 & 4,5 & 19 & 14,5 & 100 & متوسطة & مشركر دجاج \\
\hline 5 & 45,2 & 10,9 & 0,3 & 2 & 3,1 & حبة كبيرة & خيار \\
\hline 1,6 & 69,2 & 11,6 & 0,9 & 3,6 & 28 & رغبف & خبز اسمر \\
\hline 14,3 & 71,8 & 19,1 & 0,2 & 0,4 & 138 & متوسطة & تفاحة \\
\hline
\end{tabular}

مجموع السعرات الحرارية (1899.75) 
الثدة:50\%

الوقت الكلي/40-42 دقيقة
الاسبوع الاول

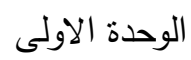

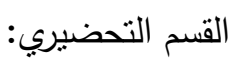

الاحماء العام/ الوقت: 10 دقائق

مشي ، والهرولة وتتخلاها تمارين عامة للساقين والذراعين •

الاحماء الخاص/ الوقت: 5 دقيقة.

تمارين للرقبة، تمارين للذراعين ، تمارين الجذع ، تمارين للساقين. تمارين الجذع ، والساقين .

القسم الرئيسي:

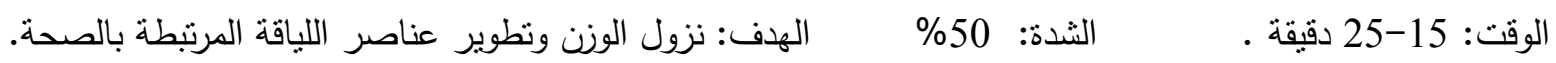
- الوقوف فتحا-ذرعان جانبا مع مسك التقل بكلتا اليدين مع تقاطع الذراعين للاعلى. التكرار / 10تكرارات - الاستلقاء على الظهر الساقان ممدودة والذراعان ممدودة اعلى الراس النهوض لتمس اليدان الرجل. التكرار/9 - الانبطاح على البطن والساقان ممدودة والذراعان مددودة امام الراس رفع الذراعين والصدر والراس لاعلى والهبوط. التكرار / 6 تكرارات.

-الوقوف مع فتحة مناسب للساقين (بعرض الكتف) الذراعين ممدودة للجانب مع وضع عصا بين الذراعين وفتل الجذع الى جهة اليمين واليسار . التكرار/ 18 تكرارات. - الصعود والنزول على المصطبة مع تتاوب الساقين من وضع التخصر . لتكرار / 8 نكرارات. تمارين ( تعمل فيها الذراعين والساقين من الققز).التكرار/ 8 تكرارات.

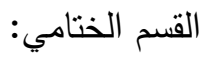
الوقت :10 دقيقة الهذف: الاسترخاء والتهدئة - (الجلوس الطويل)(سحب الساقين من الامشاط). رفع الذراعين الى الاعلى. نشر الذراعين للجانب. - (الاستلقاء )، سحب الساقين نحو الصدر .، رفع الساقين لاعلى واهتزازها.

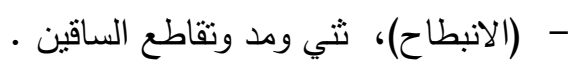

الاسبوع الثاني، والثالث، والرابع، والخامس، والسادس، والسابع، والثنامن يتبع تسلسل القسم الرئيسي مع تغيير الثدة وتغيير القسم التحضيري والختامي. 